\title{
Carine Barbafieri, Atrée et Céladon. La galanterie dans le théâtre tragique de la France classique (1634-1702)
}

\section{Daniela Dalla Valle}

\section{(2) OpenEdition}

\section{Edizione digitale}

URL: https://journals.openedition.org/studifrancesi/45747

DOI: 10.4000/studifrancesi.45747

ISSN: 2421-5856

\section{Editore}

Rosenberg \& Sellier

\section{Edizione cartacea}

Data di pubblicazione: 1 octobre 2007

Paginazione: 434-435

ISSN: 0039-2944

\section{Notizia bibliografica digitale}

Daniela Dalla Valle, «Carine Barbafieri, Atrée et Céladon. La galanterie dans le théâtre tragique de la France classique (1634-1702)», Studi Francesi [Online], 152 (LI | II) | 2007, online dal 30 novembre 2015, consultato il 24 novembre 2021. URL: http://journals.openedition.org/studifrancesi/45747 ; DOI: https://doi.org/10.4000/studifrancesi.45747

Questo documento è stato generato automaticamente il 24 novembre 2021.

\section{(c)}

Studi Francesi è distribuita con Licenza Creative Commons Attribuzione - Non commerciale - Non opere derivate 4.0 Internazionale. 


\title{
Carine Barbafieri, Atrée et Céladon. La galanterie dans le théâtre tragique de la France classique (1634-1702)
}

\author{
Daniela Dalla Valle
}

\section{NOTIZIA}

CARINE BARBAFIERI, Atrée et Céladon. La galanterie dans le théâtre tragique de la France classique (1634-1702), Rennes, PUR, 2006, pp. 391.

1 Lo studio di Carine Barbafieri si articola su un periodo relativamente lungo del teatro tragico francese, che viene inserito sotto la definizione di "classico". In particolare, esso si propone di analizzare la presenza della "galanteria" a livello teatrale. I due nomi che costituiscono il titolo suggeriscono la coincidenza di tematiche tragiche e pastorali, suggerendo l'identificazione di personaggi tragici al tempo stesso «policés et amoureux».

2 Lo studio è costruito in tre parti: la prima suggerisce la «constitution d'un mythe critique». Incomincia ad analizzare il rifiuto dell'eroe galante (in opere di d'Aubignac, di Boileau, di Voltaire), la contestazione dell'episodio amoroso, infine il contrasto fra la passione amorosa e la «moralité du théâtre», attraverso numerosi testi critici. La seconda parte si propone di analizzare «la tentation galante», in particolare «les charmes de la douceur», sia che si tratti del linguaggio galante dei personaggi tragici, oppure del gusto delle lacrime, per seguire poi - in alcuni autori - la continuità dell'ideale galante nella tragedia (da Benserade a Gilbert, a Quinault, a Pradon e a Campistron). La terza e ultima parte propone il «dilemme de la tragédie», cercando di analizzare la difficile conciliazione fra l'ideale galante e l'ideale tragico, soffermandosi anche sulla ricerca di un patetico al di fuori dell'amore, per concentrarsi alla fine sull'abbandono dell'episodio amoroso, sull'inserimento della musica o sull'amplificazione e l'estensione dei soggetti. 
3 Lo studio è molto interessante e suggestivo, sia per l'incrociarsi dello studio di testi critici e di testi drammatici, sia per l'identificazione di un modello tragico adeguatamente definito e precisato.

4 Ricca la bibliografia. 